IZA DP No. 9330

Strive to be First or Avoid Being Last:

An Experiment on Relative Performance Incentives

E. Glenn Dutcher

Loukas Balafoutas

Florian Lindner

Dmitry Ryvkin

Matthias Sutter

September 2015 


\title{
Strive to be First or Avoid Being Last: An Experiment on Relative Performance Incentives
}

\author{
E. Glenn Dutcher \\ University of Central Missouri
}

Loukas Balafoutas

University of Innsbruck

\author{
Florian Lindner \\ University of Innsbruck
}

\author{
Dmitry Ryvkin \\ Florida State University
}

Matthias Sutter

University of Cologne,

University of Innsbruck and IZA

\section{Discussion Paper No. 9330 \\ September 2015}

\author{
IZA \\ P.O. Box 7240 \\ 53072 Bonn \\ Germany \\ Phone: +49-228-3894-0 \\ Fax: +49-228-3894-180 \\ E-mail: iza@iza.org
}

\begin{abstract}
Any opinions expressed here are those of the author(s) and not those of IZA. Research published in this series may include views on policy, but the institute itself takes no institutional policy positions. The IZA research network is committed to the IZA Guiding Principles of Research Integrity.

The Institute for the Study of Labor (IZA) in Bonn is a local and virtual international research center and a place of communication between science, politics and business. IZA is an independent nonprofit organization supported by Deutsche Post Foundation. The center is associated with the University of Bonn and offers a stimulating research environment through its international network, workshops and conferences, data service, project support, research visits and doctoral program. IZA engages in (i) original and internationally competitive research in all fields of labor economics, (ii) development of policy concepts, and (iii) dissemination of research results and concepts to the interested public.
\end{abstract}

IZA Discussion Papers often represent preliminary work and are circulated to encourage discussion. Citation of such a paper should account for its provisional character. A revised version may be available directly from the author. 
IZA Discussion Paper No. 9330

September 2015

\section{ABSTRACT \\ Strive to be First or Avoid Being Last: An Experiment on Relative Performance Incentives}

We utilize a laboratory experiment to compare effort provision under optimal tournament contracts with different distributions of prizes which motivate agents to compete to be first, avoid being last, or both. We find that the combined tournament contract incorporating both incentives at the top and at the bottom induces the highest effort, especially in larger groups. Avoiding being last produces the lowest variance of effort and is more effective at motivating employees compared to competing for the top.

JEL Classification: M52, J33, J24, D24, C90

Keywords: tournament, winner, loser, contract, experiment, learning

Corresponding author:

E. Glenn Dutcher

Department of Economics, Finance and Marketing

University of Central Missouri

108 W South St.

Warrensburg, MO 64093

USA

E-mail: dutcher@ucmo.edu 


\section{Introduction}

Managers in organizations have many motivational tools at their disposal. One popular such tool is the use of incentive schemes based on ordinal relative performance evaluations, or rank-order tournaments. A recent Wall Street Journal (WSJ) article states that at least $60 \%$ of Fortune 500 companies currently use some kind of a ranking system - both for top and bottom performing employees - for incentive provision. ${ }^{1}$ The popularity of such mechanisms is largely due to an inherent structure present in most organizations, where only a limited number of promotions (or bonuses) or demotions exist. With this natural limitation, managers must be selective in who receives the top and bottom prizes. ${ }^{2}$ This selectivity motivates the employees to work harder to be the best or to avoid being the worst.

Given the prevalence of tournament-based incentive systems in organizations, it is no wonder that this topic has generated a magnitude of research (see for example, surveys by Konrad 2009 and Dechenaux, Kovenock and Sheremeta 2012). However, most of the literature on rank-order tournaments focuses on understanding how participants compete for the top prize(s) and relatively little research has been done on the incentive schemes motivating participants to avoid being last. Given the presence of last place incentives in the workplace, the lack of research on this topic constitutes a gap in our understanding of organizations. For instance, the aforementioned WSJ article states that in addition to using a tournament mechanism to reward top performers, when Country Wide had to lay off employees, they first selected those who were ranked the lowest from prior evaluations. Though termination is the most severe consequence of being ranked last, it need not be the only one. It is often the case that lower ranked employees are demoted, assigned to less desirable tasks, have bonuses withheld, etc. Additionally, little research has been directed at understanding how participants behave in a tournament with more than two distinct prizes. $^{3}$ As evidenced by the multiple exchanges and heated discussions on the topic in the popular press, understanding these two key elements of organizational tournaments is paramount to the discussion of rank-order tournaments.

A clean identification of the incentive effects of tournaments is quite difficult, since

\footnotetext{
${ }^{1}$ The article titled "'Rank and Yank' Retains Vocal Fans"was published on January 31, 2012 and can be accessed at http://online.wsj.com/article/SB10001424052970203363504577186970064375222.html.

${ }^{2}$ As pointed out by Lazear and Rosen (1981), further reasons for the popularity of rank-order tournaments have to do with complications inherent in many organizations, which inhibit a manager from forming contracts on effort directly due to the difficulties in measuring actual output in a quantifiable way; the manager may also be willing to insure workers against common productivity shocks.

${ }^{3}$ This is the hallmark of Jack Welch's "differentiation" management strategy which has been widely adopted. For his defense of such a mechanism, see a recent piece by him at http://online.wsj.com/news/articles/SB10001424052702303789604579198281053673534.
} 
data collected in the field usually allow one to observe only outcomes (e.g., total output). This is problematic since in most instances outcomes are a function of luck, noise, ability and endogenous selection as well as effort. Due to the difficulties in isolating the incentive effects, laboratory experiments have often been utilized as a way of giving more control to the researcher. A brief review of these experiments is given in Section 2. As already noted, the focus of experimental research has been mainly on competition for the top prize(s) or two distinct prizes.

The main contribution of this paper is in providing a detailed empirical comparison of tournament mechanisms involving competition for the top, competition to avoid the bottom, or both in a setting with efficient principal-agent contracts. Using the prominent framework of Lazear and Rosen (1981) we define three tournament mechanisms that differ in how rank-based prizes are allocated. A winner tournament is a mechanism where the agents compete to be first and one top prize is awarded to the agent with the highest output. Likewise, in a loser tournament the agents compete to avoid being last and one bottom prize is given to the agent with the lowest output. Finally, a winnerEjloser tournament is a combination of the two. For each of these mechanisms, we compute optimal principal-agent contracts that generate the same efficient levels of effort. We then parameterize the theoretical model and directly use the optimal contracts derived from it in a laboratory experiment, in which subjects in the role of employees choose effort levels (tied to a convex cost structure) and compete in one of the three mechanisms defined above. ${ }^{4}$ Previous contest experiments documented substantial between- and within-subject heterogeneity and off-equilibrium behavior (for a review, see Sheremeta 2013); therefore, we also introduce an alternative set of predictions using a Quantal Response Equilibrium (QRE; McKelvey and Palfrey 1995) model in the Lazear-Rosen framework.

We also vary the size of the tournament, considering tournaments in groups of three and six agents. Varying the size of the tournament serves two primary purposes. First, tournaments in organizations vary in size. Understanding how the different mechanisms interact with the size of the tournament is relevant to forming generalizable recommendations. Second, varying the number of contestants in the tournament will help us to disentangle the underlying causes of the differences observed between mechanisms, and will also provide robustness to our results.

Our findings show that, in line with QRE predictions but not the Nash equilibrium predictions, the winner tournament is inferior to the other two in terms of effort. The existence of a top prize in the winner tournament encourages stiff competition for the top prize which, in turn, leads to a large number of subjects responding by choosing very low

\footnotetext{
${ }^{4}$ Note that the chosen effort design element was selected to better test the base theory.
} 
efforts - a finding which is consistent with the prior literature. In contrast, the mechanism which only includes a single bottom prize practically eliminates effort choices in the lowest range while simultaneously discouraging subjects from providing very high effort. These two findings lead naturally to our result that the mechanism which combines both a top prize and a bottom prize brings out the best of both effects and no other mechanism generates higher effort. Under this scheme, competition away from the bottom reduces the number of subjects who choose low effort, while the competition for the top provides continuous encouragement for some subjects to choose very high effort. Overall, the QRE model does better than the Nash equilibrium as it correctly predicts that the lowest effort and highest effort variance will occur in the winner tournament. The superiority of the winner\&loser tournament, however, is not predicted by the basic model or the QRE model.

Given that some of the treatment differences are not predicted by the two models, we computed subjects' best responses and measured how far away each subject was from their best response and whether they improved over time. We find that in the winner tournaments, subjects were the furthest from their best response and, quite surprisingly, in contests of both sizes, they got worse over time. Even though subjects still did not best respond in the loser and winner\&loser tournaments, there is no difference in the deviations from best response between these two mechanisms.

In terms of a direct comparison of winner and loser tournaments, we find that the loser tournament is overall a better motivator than the winner tournament. We also find that round-by-round adjustment is in line with the predictions generated by a basic learning theory. Thus, since avoiding being last is such a strong motivator, and the probability of being last is greater in smaller tournaments, the outcome in the loser tournament approaches that of the winner\&loser tournament in contests of size three. The strong learning effect we find also suggests that a manager using a rank-order pay scheme must use the mechanism regularly as the increases in work effort will decline if the incentives are absent.

\section{Brief review of the related literature}

Extensive theoretical work has been undertaken to understand rank-order tournaments in an organizational setting. This literature has mainly focused on winner tournaments (see reviews by McLaughlin 1988; Lazear 1995 and Konrad 2009). ${ }^{5}$ Loser tournaments were

\footnotetext{
${ }^{5}$ Our main interest is in the static principal-agent models of tournaments á la Lazear and Rosen (1981). Dynamic tournaments which involve sequential elimination of employees have also been explored (see,
} 
first mentioned by Mirrlees (1975), while Nalebuff and Stiglitz (1983) prove the equivalence of the two schemes in the more general symmetric setting. Loser tournaments have more recently started to attract theoretical examinations by authors looking at heterogeneity in some aspect (e.g. Kräkel 2000, Gürtler and Kräkel 2011, Moldovanu, Sela and Shi 2012 and Balafoutas et al. 2012) or the effects of risk-aversion (Akerlof and Holden 2012).

Many tournament and contest experiments have also been conducted (see a review by Dechenaux, Kovenock and Sheremeta 2012). The first study to examine rank-order tournaments, conducted by Bull, Schotter and Weigelt (1987), found that tournament and piece-rate pay schemes generated the same mean effort, though the tournament pay scheme induced a higher variance in effort. With this very basic tenant of tournament theory established, subsequent papers focused on other topics such as affirmative action (Schotter and Weigelt 1992), tournament size and prize structure (Harbring and Irlenbusch 2003, Orrison, Schotter and Weigelt 2004), sabotage (Harbring and Irlenbusch 2008, Falk, Fehr and Huffman 2008, Carpenter, Matthews and Schirm 2010, Harbring and Irlenbusch 2012), selection (Camerer and Lovallo 1999, Eriksson, Teyssier and Villeval 2009, Cason, Masters and Sheremeta 2010, Müller and Schotter 2010), dynamic tournaments (Sheremeta 2010), and gender effects (Gneezy, Niederle and Rustichini 2003) among others. In what follows we focus on the studies that vary the number of winner prizes and/or the number of contestants in rank-order tournaments.

The two prior studies that are most relevant to our study (Orrison, Schotter and Weigelt 2004, Harbring and Irlenbusch 2008) vary the fraction of winner and loser prizes in tournaments of different sizes. The overall finding in these papers is that the highest effort is observed when there is an equal distribution of winner and loser prizes. This is counter to Harbring and Irlenbusch (2003) who show that in a capped all-pay auction setting, effort increases with the number of winner prizes. Both Orrison, Schotter and Weigelt (2004) and Harbring and Irlenbusch (2008) find no discernible trend that relates effort to the size of the contest. Using non-uniform distributions of noise, List et al. (2010) support this result for risk-neutral subjects, but find that risk-averse subjects' effort declines as the number of contestants increases.

Although these papers have treatments that are similar in concept to our design, key differences remain between them and our study due to the disparate research questions. First, the above studies only implement two levels of prizes. In our design, we will implement a treatment with a top, middle and bottom prize (the winner\&loser tournament).

e.g., Rosen 1986, O'Flaherety and Siow 1995, Gradstein and Konrad 1999, Ryvkin and Ortmann 2008, Casas-Arce and Martinez-Jerez 2009, Sunde 2009, Höchtl et al. 2014). Even though the elimination mechanism can be thought of as a loser tournament, the focus of these papers is not on this aspect, but on the effect elimination has on the remaining agents. 
This is an important variation for several reasons. Since most organizations typically use incentive schemes which have consequences for the best and the worst workers (see the above references from the WSJ), it is important to understand how effort and efficiency may differ under this very common pay scheme which uses three distinct levels of prizes. We will show that including three distinct prizes is essential since managers who choose this pay scheme can typically expect higher effort. Second, and more importantly, since the above papers were not intended to test the differences between competition for the top or away from the bottom, they do not use optimal contracts - a feature which would be necessary for a meaningful comparison, and is a potential cause of the seemingly contradictory results of the papers mentioned above. More specifically, optimal contracts are important since they fix the amount of money paid per worker to be equal in every setting while holding constant the predicted efficient level of effort. Thus, differences between the pay schemes that we observe can be attributed to the underlying behavioral response to winner and/or loser incentives, and the relative efficiency of the three schemes can be cleanly examined.

\section{The model}

\subsection{Three tournament mechanisms}

We model tournament mechanisms following the approach of Lazear and Rosen (1981). There are $n \geq 2$ identical risk-neutral agents indexed by $i=1, \ldots, n{ }^{6}$ Each agent participates in the tournament by exerting effort $e_{i} \geq 0$. The cost of effort $e_{i}$ to agent $i$ is $c g\left(e_{i}\right)$, where $c>0$ is the agents' homogeneous cost parameter, and function $g(\cdot)$ is strictly increasing and strictly convex.

Agent $i$ 's output is $y_{i}=e_{i}+u_{i}$, where $u_{i}$ is a zero-mean idiosyncratic random shock. It is assumed that shocks $u_{1}, \ldots, u_{n}$ are i.i.d. across agents and drawn from a distribution with support $\left[u_{l}, u_{h}\right]$, pdf $f(u)$ and $\operatorname{cdf} F(u)$.

In tournament mechanisms, agents are evaluated on the basis of their relative performance. Effort is not observable and cannot be used for contracting. Moreover, cardinal output is also not observable. Tournament contracts are profiles of fixed prizes based on

\footnotetext{
${ }^{6}$ Considering risk-averse agents would complicate the analysis substantially (see Akerlof and Holden 2012). The optimal allocation of prizes would depend on the shape of the agents' utility functions, which implies that the experiment cannot be calibrated ex ante. We, therefore, have chosen to formulate our theoretical predictions in a simpler risk-neutral setting and control for risk aversion econometrically in a reduced form. To assuage some concerns, the effect of risk aversion is minimized in our experiment because we pay subjects for 4 randomly selected rounds. We find that neither risk nor loss aversion parameters are statistically significant in subjects' choices of effort (see Table 2 below).
} 
ordinal comparisons of agents' output levels. Let $w_{r}$ denote the prize of the agent whose output is ranked $r$, with $w_{1} \geq w_{2} \geq \ldots \geq w_{n}$. The expected payoff of agent $i$ can then be written as

$$
\pi_{i}(\mathbf{e})=\sum_{r=1}^{n} p^{(i, r)}(\mathbf{e}) w_{r}-c g\left(e_{i}\right), \quad i=1, \ldots, n .
$$

Here, $\mathbf{e}=\left(e_{1}, \ldots, e_{n}\right)$ is the vector of all agents' effort levels; $p^{(i, r)}(\mathbf{e})$ denotes the probability, given e, that player $i$ 's output is ranked $r$, with $\sum_{r} p^{(i, r)}(\mathbf{e})=1 .^{7}$ Assuming all agents participate in the tournament with positive efforts, ${ }^{8}$ the vector of equilibrium effort levels, $\mathbf{e}^{*}=\left(e_{1}^{*}, \ldots, e_{n}^{*}\right)$, solves the system of first-order conditions ${ }^{9}$

$$
\sum_{r=1}^{n} \frac{\partial p^{(i, r)}(\mathbf{e})}{\partial e_{i}} w_{r}=c g^{\prime}\left(e_{i}\right), \quad i=1, \ldots, n .
$$

We consider three tournament mechanisms: winner tournaments, loser tournaments, and winner\&loser tournaments. In winner tournaments, the agent with the highest output receives a prize $w_{1}=V_{1}$, while all other agents receive a prize $w_{2}=\ldots=w_{n}=V_{2}<V_{1}$. Using the restriction $\sum_{r} p^{(i, r)}=1$, Eq. (2) simplifies to

$$
\left(V_{1}-V_{2}\right) \frac{\partial p^{(i, 1)}(\mathbf{e})}{\partial e_{i}}=c g^{\prime}\left(e_{i}\right), \quad i=1, \ldots, n .
$$

In loser tournaments, the agent with the lowest output receives a prize $w_{n}=W_{2}$, while all other agents receive a prize $w_{1}=\ldots=w_{n-1}=W_{1}>W_{2}$. Eq. (2) then gives

$$
-\left(W_{1}-W_{2}\right) \frac{\partial p^{(i, n)}(\mathbf{e})}{\partial e_{i}}=c g^{\prime}\left(e_{i}\right), \quad i=1, \ldots, n
$$

In winnerËloser tournaments, the agent with the highest output receives a prize $w_{1}=S_{1}$, the agent with the lowest output receives a prize $w_{n}=S_{3}$, and all other agents receive a prize $w_{2}=\ldots=w_{n-1}=S_{2}$, with $S_{3}<S_{2}<S_{1}$. Eq. (2) gives

$$
\left(S_{1}-S_{2}\right) \frac{\partial p^{(i, 1)}(\mathbf{e})}{\partial e_{i}}-\left(S_{2}-S_{3}\right) \frac{\partial p^{(i, n)}(\mathbf{e})}{\partial e_{i}}=c g^{\prime}\left(e_{i}\right), \quad i=1, \ldots, n
$$

In order to derive optimal contracts, suppose there is a risk-neutral principal, whose

\footnotetext{
${ }^{7}$ For simplicity, we assume that the probability of ties is zero. This is justified if the pdf of the distribution of noise is continuous.

${ }^{8}$ Note that participation in the tournament with zero effort is not equivalent to non participation. Because of noise, the probability of winning the tournament with zero effort is still positive.

${ }^{9}$ The first-order conditions are necessary but not sufficient for the equilibrium in pure strategies to exist. In the experiment, we choose parameters so that the equilibrium exists, cf. Section 4.3.
} 
expected payoff (firm's profit) is defined as the difference between aggregate effort and total prize payments: $\Pi=\sum_{i} e_{i}-V_{1}-(n-1) V_{2}$ for winner tournaments, $\Pi=\sum_{i} e_{i}-(n-$ 1) $W_{1}-W_{2}$ for loser tournaments, and $\Pi=\sum_{i} e_{i}-S_{1}-(n-2) S_{2}-S_{3}$ for winner\&loser tournaments. In the derivation of optimal contracts, we follow the approach of Lazear and Rosen (1981) and assume that the principal operates in a (buyer-side) competitive labor market under the zero-profit condition $\Pi=0$.

\subsection{Symmetric optimal contracts}

We restrict the analysis to the symmetric case in which all agents exert the same effort in equilibrium. Let $\beta_{r}=\left[\partial p^{(i, r)} / \partial e_{i}\right]_{\text {sym }}$ denote the derivatives of $p^{(i, r)}$ evaluated for symmetric efforts. As shown by Akerlof and Holden (2012), coefficients $\beta_{r}$ are independent of effort and given by

$$
\beta_{r}=\left(\begin{array}{l}
n-1 \\
r-1
\end{array}\right) \int F(t)^{n-r-1}[1-F(t)]^{r-2}[n-r-(n-1) F(t)] f(t)^{2} d t .
$$

For winner tournaments, the symmetrized first-order condition (3) for agents' equilibrium effort, $\bar{e}$, becomes

$$
\left(V_{1}-V_{2}\right) \beta_{1}=c g^{\prime}(\bar{e}), \quad \beta_{1}=(n-1) \int F(t)^{n-2} f(t)^{2} d t
$$

Equation (7) has a unique solution $\bar{e}>0$ provided $\left(V_{1}-V_{2}\right) \beta_{1}>c g^{\prime}(0)$. The principal's profit is $\bar{\Pi}=n \bar{e}-V_{1}-(n-1) V_{2}$, which implies, under the zero-profit condition, $\bar{e}=$ $V_{1} / n+(n-1) V_{2} / n$, and the agents' expected payoffs are $\bar{\pi}=\bar{e}-c g(\bar{e})$. As in Lazear and Rosen (1981), we assume that the principal chooses prizes $V_{1}$ and $V_{2}$ to maximize $\bar{\pi}$, implying $\left(1-c g^{\prime}(\bar{e})\right) \partial \bar{e} / \partial V_{k}=0, k=1,2$. This gives the following system of equations for the optimal contract:

$$
\left(V_{1}-V_{2}\right) \beta_{1}=c g^{\prime}(\bar{e}), \quad n \bar{e}=V_{1}+(n-1) V_{2}, \quad c g^{\prime}(\bar{e})=1
$$

For loser tournaments, the symmetric first-order condition for agents' equilibrium effort, $\tilde{e}$, is

$$
-\left(W_{1}-W_{2}\right) \beta_{n}=c g^{\prime}(\tilde{e}), \quad \beta_{n}=-(n-1) \int[1-F(t)]^{n-2} f(t)^{2} d t
$$

Equation. (9) has a unique solution $\tilde{e}>0$ provided $\left(W_{1}-W_{2}\right)\left|\beta_{n}\right|>c g^{\prime}(0)$. The principal's profit is $\tilde{\Pi}=n \tilde{e}-(n-1) W_{1}-W_{2}$. Similar to winner tournaments, the zero-profit condition 
and maximization of agents' expected payoff leads to the system of equations for optimal contracts $\left(W_{1}, W_{2}\right)$ :

$$
\left(W_{1}-W_{2}\right)\left|\beta_{n}\right|=c g^{\prime}(\tilde{e}), \quad n \tilde{e}=(n-1) W_{1}+W_{2}, \quad c g^{\prime}(\tilde{e})=1
$$

For winner\&loser tournaments, the symmetric first-order condition for agents' equilibrium effort, $\hat{e}$, is

$$
\left(S_{1}-S_{2}\right) \beta_{1}-\left(S_{2}-S_{3}\right) \beta_{n}=c g^{\prime}(\hat{e}) .
$$

The principal's profit is $\hat{\Pi}=n \hat{e}-S_{1}-(n-2) S_{2}-S_{3}$. Similar to the other two incentive schemes, the zero-profit condition and maximization of agents' expected payoff leads to the system of equations for optimal contract $\left(S_{1}, S_{2}, S_{3}\right)$ :

$$
\left(S_{1}-S_{2}\right) \beta_{1}+\left(S_{2}-S_{3}\right)\left|\beta_{n}\right|=c g^{\prime}(\hat{e}), \quad n \hat{e}=S_{1}+(n-2) S_{2}+S_{3}, \quad c g^{\prime}(\hat{e})=1
$$

Comparing Eqs. (8), (10) and (12), it is seen that the equilibrium effort is the same under the optimal contracts for all three mechanisms: $\bar{e}=\tilde{e}=\hat{e}$. All three optimal contracts are socially efficient. Individual effort $\bar{e}$ is determined by condition $c g^{\prime}(\bar{e})=1$, and the optimal prizes can be expressed in terms of $\bar{e}$.

For winner tournaments, the optimal contract is

$$
\bar{V}_{1}=\bar{e}+\frac{n-1}{n \beta_{1}}, \quad \bar{V}_{2}=\bar{e}-\frac{1}{n \beta_{1}} .
$$

For loser tournaments, the optimal contract is

$$
\bar{W}_{1}=\bar{e}+\frac{1}{n\left|\beta_{n}\right|}, \quad \bar{W}_{2}=\bar{e}-\frac{n-1}{n\left|\beta_{n}\right|} .
$$

For winner\&loser tournaments, the number of independent equations for the optimal contract is the same as for the other two mechanisms, but there are three prizes to be determined. This is a manifestation of the more general result, mentioned by Lazear and Rosen (1981), that a tournament mechanism involving any number of prizes between 2 and $n$ can be implemented with only two distinct prizes under symmetry and risk neutrality. Any $S_{2}$ between $S_{3}$ and $S_{1}$ can be implemented as the intermediate prize. For convenience, we choose $S_{2}=\left(S_{1}+S_{3}\right) / 2$. Equations in (12) then give the following optimal contract:

$$
\bar{S}_{1}=\bar{e}+\frac{1}{2 \hat{\beta}}, \quad \bar{S}_{2}=\bar{e}, \quad \bar{S}_{3}=\bar{e}-\frac{1}{2 \hat{\beta}} ; \quad \hat{\beta}=\frac{\beta_{1}+\left|\beta_{n}\right|}{2}
$$




\section{Experimental design and predictions}

\subsection{Basics}

All experiments were conducted at the University of Innsbruck lab using z-Tree (Fischbacher, 2007). We recruited 216 subjects (50\% female) from the standard student subject pool using the online announcement system ORSEE (Greiner, 2004). We conducted 12 sessions with 18 subjects in each session. Sessions lasted approximately one hour, and subjects earned $€ 9.36$ on average (without a show-up fee).

\subsection{Treatments}

The experiment follows a $3 \times 2$ between-subject design covering three tournament mechanisms: winner (WIN), loser (LOS) and winner\&loser (W\&L); and two group sizes: $n=3$ and $n=6$. The resulting six treatments will be referred to as WIN3, LOS3, W\&L3, WIN6, LOS6 and W\&L6. The procedure used for all six treatments was the same. Once subjects were seated in the lab, they were handed printed instructions which were also read aloud to ensure common knowledge of the rules of the game. ${ }^{10}$ The first part of the experiment consisted of 20 rounds, and in each round subjects were randomly and anonymously matched in a group with other participants in the session. ${ }^{11}$ Each round the subjects participated in a chosen effort task. Effort choices had a convex cost structure associated with them. ${ }^{12}$

A uniform discrete zero-mean random number was added to each agent's chosen effort number, resulting in their "total number." 13 Their total number was then compared to the total number of the other agents in their group to determine their rank within the group. In WIN3 and WIN6, the agent with the highest rank received the top prize while all others received the bottom prize. In LOS3 and LOS6, the agent with the lowest rank received the bottom prize while all others received the top prize. In W\&L3 and W\&L6 the agent with the highest rank received the top prize, the agent with the lowest rank received the bottom prize, and all others received the middle prize. The total payoff in a round was calculated by subtracting the cost of the chosen effort number from the

\footnotetext{
${ }^{10}$ Sample instructions for WIN6 are given in the Appendix.

${ }^{11}$ Random rematching was implemented to reduce reputation effects and mimic the one-shot setting as closely as possible. Since our main interest lies in understanding how people compete to avoid being last compared to how they compete to be first, including reputation in this design would cloud the main interest of the paper.

${ }^{12} \mathrm{At}$ the end of the instruction sheet there was a table showing the cost associated with each effort level. The cost table is given in the Appendix.

${ }^{13}$ The random number was drawn randomly and independently for every agent in each round.
} 
prize gained. Effort costs and prizes were denominated in tokens, with 2000 tokens $=€ 1$. Once all subjects in the session had chosen their effort number, they were informed of their random number, their total number and whether their total number was the highest (in WIN3, WIN6, W\&L3 and W\&L6) or the lowest (in LOS3, LOS6, W\&L3 and W\&L6). Additionally, they were informed of their payment for that round if it would be randomly selected for payment. Four rounds were chosen at random for payment at the conclusion of the experiment. ${ }^{14}$ After the last round, we elicited, in an incentivized manner, subjects' beliefs about each of the other group members' effort choices in that round.

Before receiving feedback at the end of the experiment, subjects were administered a risk-aversion task (Holt and Laury 2002) and a loss-aversion task (Gächter, Johnson and Herrmann 2010), both of them incentivized. The experiment concluded with a short demographic questionnaire.

\subsection{Parameters of the experiment}

For comparability between the tournament mechanisms, we chose the parameters of the experiment in accordance with the optimal contracts derived in Section 3.2. In all treatments, we used the uniform distribution of noise on the interval $[-b, b]$. In this case, $\beta_{1}=\left|\beta_{n}\right|=\hat{\beta}=1 /(2 b)$. The optimal contracts for the winner, loser and winner\&loser tournaments are

$$
\begin{aligned}
& \bar{V}_{1}=\bar{e}+\frac{2 b(n-1)}{n}, \quad \bar{V}_{2}=\bar{e}-\frac{2 b}{n}, \\
& \bar{W}_{1}=\bar{e}+\frac{2 b}{n}, \quad \bar{W}_{2}=\bar{e}-\frac{2 b(n-1)}{n}, \\
& \bar{S}_{1}=\bar{e}+b, \quad \bar{S}_{2}=\bar{e}, \quad \bar{S}_{3}=\bar{e}-b .
\end{aligned}
$$

For the cost function of effort, we used $g(e)=(A-e)^{-d}-A^{-d}$, with $A, d>0$, which gives the optimal effort $\bar{e}=A-(d c)^{1 /(d+1)}$. We used different cost functions (parameters $A, c$ and $d$ ) for $n=3$ and $n=6$, as it was difficult to find a parameterization that generated a symmetric pure-strategy equilibrium in all treatments simultaneously. This is not an issue for comparability because our main focus is on the comparison between different tournament mechanisms for a given $n$, and not on a direct comparison between the $n=3$ and $n=6$ cases. We ensured, however, that the optimal effort $\bar{e}$ was the same in all six treatments. The parameters of the experiment are summarized in Table $1 .{ }^{15}$

\footnotetext{
${ }^{14}$ Note that it was possible for a subject to lose money in a given round. By the end of the experiments, no subjects had negative total earnings.

${ }^{15}$ There are minor discrepancies in Table 1 due to rounding. In the experiment, all the prizes and costs have been multiplied by 100 to avoid the decimals.
} 


\begin{tabular}{lllllllll}
\hline Treatment & $n$ & $b$ & $c$ & $A$ & $d$ & Prizes & $\bar{e}$ & $\bar{\pi}$ \\
\hline WIN3 & 3 & 44 & 3074 & 106 & 1.4 & $V_{1}=132, V_{2}=44$ & 73.33 & 54.49 \\
LOS3 & 3 & 44 & 3074 & 106 & 1.4 & $W_{1}=102.67, W_{2}=14.67$ & 73.33 & 54.49 \\
W\&L3 & 3 & 44 & 3074 & 106 & 1.4 & $S_{1}=117.33, S_{2}=73.33, S_{3}=29.33$ & 73.33 & 54.49 \\
WIN6 & 6 & 44 & 2100 & 96.72 & 1.57 & $V_{1}=146.67, V_{2}=58.67$ & 73.33 & 60.04 \\
LOS6 & 6 & 44 & 2100 & 96.72 & 1.57 & $W_{1}=88, W_{2}=0$ & 73.33 & 60.04 \\
W\&L6 & 6 & 44 & 2100 & 96.72 & 1.57 & $S_{1}=117.33, S_{2}=73.33, S_{3}=29.33$ & 73.33 & 60.04 \\
\hline
\end{tabular}

Table 1: Treatments and parameters of the experiment.
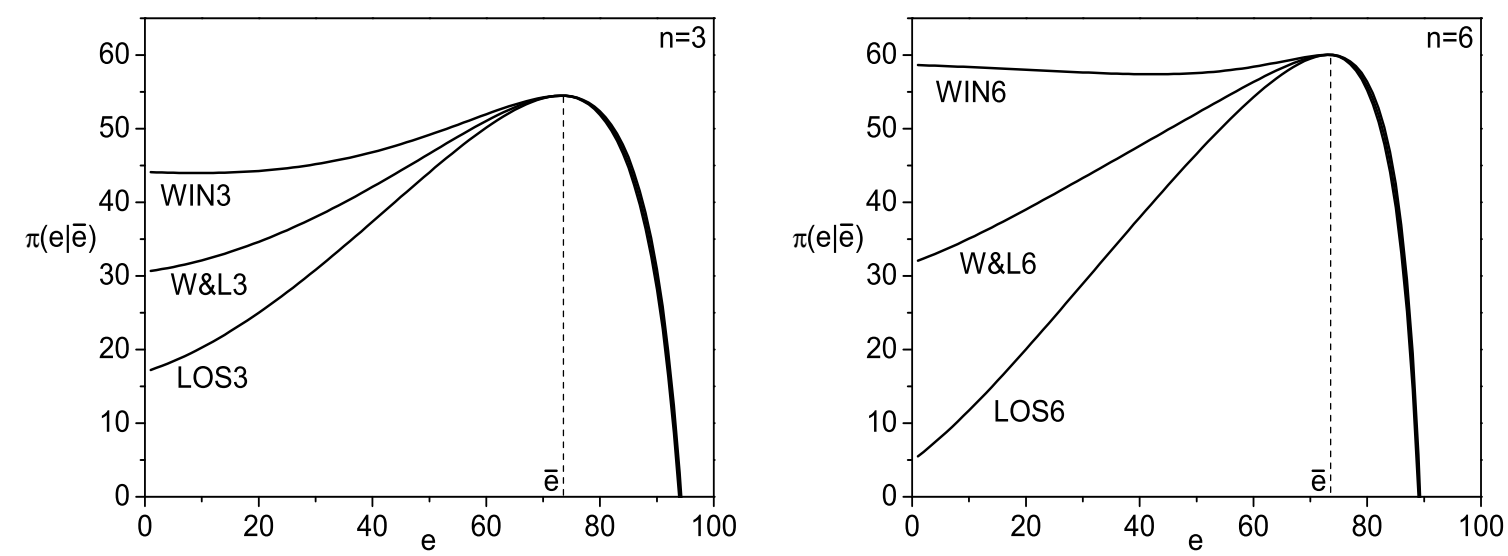

Figure 1: Expected payoff of a player as a function of her effort, with all other players' efforts fixed at $\bar{e}$. 
Figure 1 shows the expected payoff of a player, $\pi(e \mid \bar{e})$, as function of her effort, with the efforts of all other players in the group fixed at $\bar{e}$. The left panel in Figure 1 shows $\pi(e \mid \bar{e})$ for each of the three mechanisms for $n=3$, while the right panel shows the same for $n=6$. Figure 1 confirms that $\bar{e}$ is indeed the symmetric equilibrium effort level in all treatments. ${ }^{16}$

\subsection{Quantal Response Equilibrium predictions}

It is evident from Figure 1 that for effort levels below $\bar{e}$, the payoff function is very flat in the winner tournaments, especially for $n=6$, and much steeper in the loser tournaments, with the winner\&loser tournaments in between. This implies that subjects' errors, i.e., deviations from equilibrium or best response, are penalized differently in the three mechanisms. Given that the learning environment is somewhat complex and noisy in Lazear-Rosen contests, the flatness of the payoff function can help explain off-equilibrium behavior. Prior contest experiments (primarily with the prize structure of the WIN treatment) have shown that subjects exhibit substantial heterogeneity in effort choices, both between subjects and over time (for a review, see Sheremeta 2013). One widely used approach to organizing data with a large amount of off-equilibrium behavior, dispersion and experimentation is the Quantal Response Equilibrium (QRE) framework introduced by McKelvey and Palfrey (1995). ${ }^{17}$ Given that downward deviations from equilibrium are penalized the most in the loser tournaments and the least in the winner tournaments, we expect QRE distributions of effort choices to be different in the three mechanisms, with the highest expected effort in LOSn and the lowest in WIN $n$.

Formally, let $B$ denote the (finite) set of available effort levels. In the QRE framework, the symmetric equilibrium is a probability distribution $p(b)$ over $B$, with $\sum_{b \in B} p(b)=1$. Following McKelvey and Palfrey (1995), $p(b)$ satisfies the system of equations

$$
p(b)=\frac{\exp \left[\lambda \pi_{e}(b)\right]}{\sum_{b^{\prime} \in B} \exp \left[\lambda \pi_{e}\left(b^{\prime}\right)\right]}, \quad \pi_{e}(b)=\sum_{b_{2}, \ldots, b_{n} \in B} \pi\left(b, b_{-1}\right) p\left(b_{2}\right) \ldots p\left(b_{n}\right) .
$$

Here, $\pi_{e}(b)$ is the expected payoff of a player choosing effort $b ; \pi\left(b, b_{-1}\right)$ is the expected payoff of a player choosing effort $b$ given the effort choices $b_{-1}$ of other players in the group; $\lambda>0$ is the QRE noise parameter, with larger $\lambda$ corresponding to lower noise in subjects' decision making. As $\lambda \rightarrow \infty$, QRE converges to the Nash equilibrium.

\footnotetext{
${ }^{16}$ Notice that while all payoff functions $\pi(e \mid \bar{e})$ reach global maximum at $e=\bar{e}$, a local maximum at 0 is present in the $W I N n$ tournaments.

${ }^{17}$ For example, Anderson et al. (1998) and Goeree et al. (2002) discuss QRE as an explanation of overbidding in auctions, while Sheremeta (2011), Chowdhury et al. (2012), Lim et al. (2012) and Brookins and Ryvkin (2014), among others, use QRE to explain overbidding and bid dispersion in lottery contests.
} 


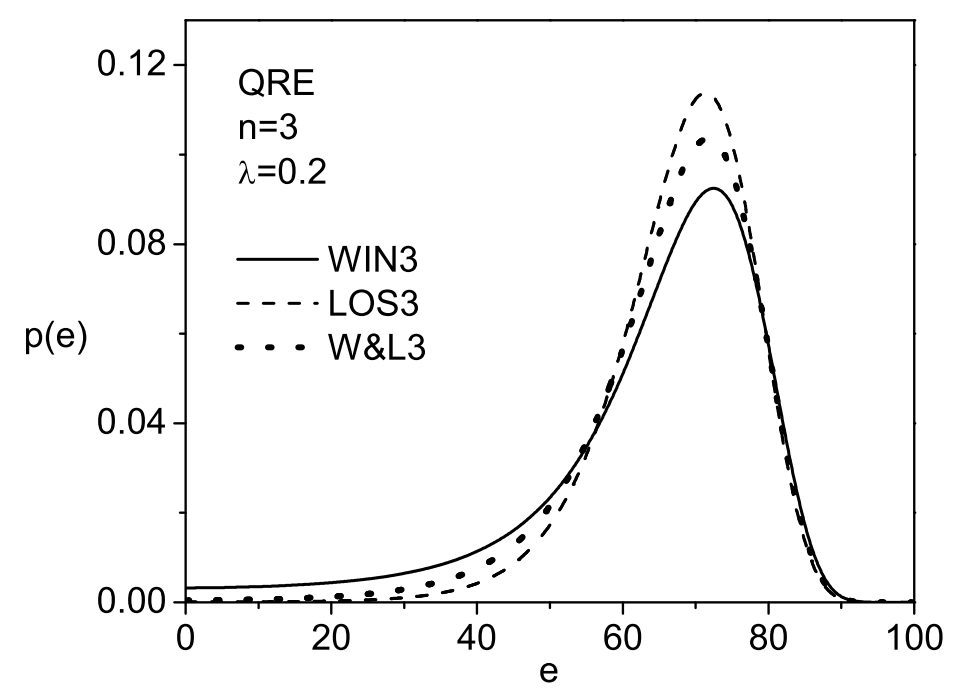

Figure 2: QRE distributions of effort, by treatment, for $n=3, \lambda=0.2$.

Figure 2 shows the QRE distributions of effort using $\lambda=0.2$ and the parameters of the experiment for $n=3$. As seen from the figure, the QRE distributions are indeed different between treatments and ordered from the highest effort in LOS3 to the lowest in WIN3. The expected QRE efforts, calculated as $\bar{e}^{\mathrm{QRE}}=\sum_{b \in B} p(b) b$, are ranked accordingly: 63.77 for WIN3, 66.45 for W\&L3 and 67.82 for LOS3. The standard deviations of effort are $16.04,9.69$ and 11.83 , respectively. ${ }^{18}$

We conclude that although the baseline model predicts the same level of effort in all treatments, the QRE model predicts differences in average effort levels, with the highest effort in LOS and lowest in WIN, and differences in the variance of effort, with the highest variance in WIN and lowest in LOS. Besides, the QRE model predicts underbidding, as compared to the Nash equilibrium effort level $\bar{e}=73.33$. This is because the profit functions decline sharply for efforts above equilibrium but are relatively flat for efforts below equilibrium (cf. Figure 1), and in contrast to lottery contests where payoff functions are flat to the right of the equilibrium and QRE predicts overbidding. Thus, the QRE model provides a unifying explanation for why overbidding is observed overwhelmingly in lottery contests, while average efforts at or below equilibrium are often observed in Lazear-Rosen contest experiments (for a review, see Dechenaux et al. 2012).

\footnotetext{
${ }^{18}$ The results for $n=6$ are qualitatively similar, with the expected QRE efforts 54.76, 68.22 and 65.31, and the standard deviations of effort 23.40, 5.89 and 10.41 in WIN6, LOS6 and W\&L6, respectively. We also experimented with different values of $\lambda$ and found that the expected QRE efforts converge to $\bar{e}$ monotonically from below as $\lambda$ increases.
} 

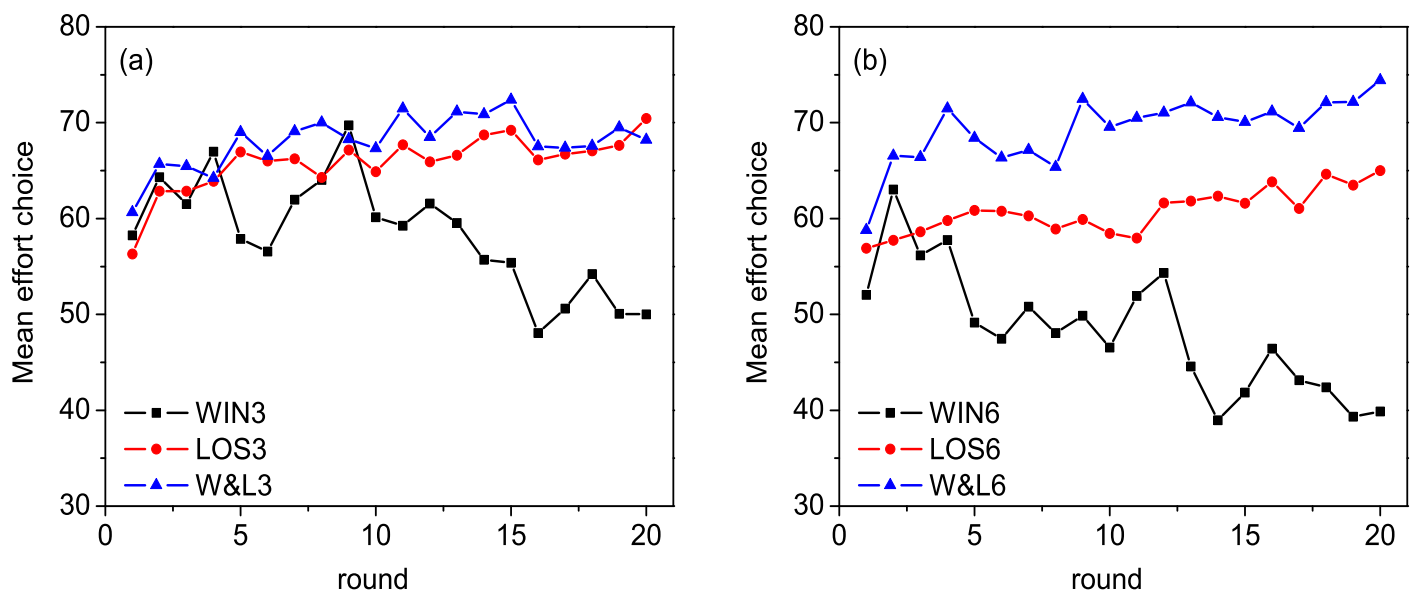

Figure 3: Mean effort over time. Panel (a): Effort in contests of size three. Panel (b): Effort in contests of size six.

\section{$5 \quad$ Experimental results}

\section{$5.1 \quad$ Effort}

We begin our analysis with an overview of the data. Figure 3 displays the average effort in each round by treatment, in contests of size three (panel a) and size six (panel b). Each point in the figure represents the average of 36 observations. Looking first at panel (a), we can see that the average effort in WIN3 is much lower than that in LOS3 or W\&L3, especially from round 10 onward, while average effort in LOS3 seems to be only slightly lower than in W\&L3. The picture is to a certain extent very similar for contests of size six: panel (b) shows that the average effort is highest in W\&L6, intermediate in LOS6, and lowest in WIN6. The mean effort in all treatments except W\&L6 is below the Nash equilibrium prediction value of $73 .^{19}$

It is already evident that the QRE model does better than the basic model, although it does not predict the exact ordering of treatments by average effort. Table 2 reports the results of OLS regressions with standard errors clustered at the session level and adjusted for the small number of clusters using the Biased-Reducing Linearization procedure (BRL) of Bell and McCaffrey (2002). The dependent variable is individual effort, while the main explanatory variables are dummies for the LOS and the W\&L treatments (which implies

\footnotetext{
${ }^{19}$ The hypothesis of average effort being equal to 73 is rejected in all treatments with $n=3(p<0.01)$. The hypothesis is also rejected for WIN6 and LOS6 $(p<0.01)$, but not for W\&L6 $(p=0.017)$. The $p$-values are obtained via Wald tests based on OLS regressions of chosen effort on treatment dummies with standard errors clustered at the session level and adjusted using the Biased-Reducing Linearization (BRL) procedure (Bell and McCaffrey, 2002).
} 


\begin{tabular}{lcc}
\hline Effort & $(\mathbf{1})$ & $\mathbf{( 2 )}$ \\
& $\mathrm{n}=3$ & $\mathrm{n}=6$ \\
\hline Constant & $49.4^{* * *}$ & $67.64^{* * *}$ \\
& $(12.47)$ & $(21.89)$ \\
LOS & $7.77^{* * *}$ & $11.38^{* * *}$ \\
& $(2.82)$ & $(3.87)$ \\
W\&L & $9.59^{* * *}$ & $20.47^{* * *}$ \\
Age & $(2.88)$ & $(2.45)$ \\
& 0.31 & -0.53 \\
Risk Aversion & $(0.48)$ & $(0.70)$ \\
Loss Aversion & 0.76 & 0.63 \\
& $(0.78)$ & $(0.53)$ \\
Female & 0.21 & -1.26 \\
& $(0.99)$ & $(0.87)$ \\
Round & -1.44 & -3.53 \\
& $(3.22)$ & $(2.75)$ \\
\# of observations & 2160 & -0.05 \\
\# of clusters & 6 & 6 \\
\hline
\end{tabular}

Table 2: OLS regression results. Standard errors, clustered by session and BRL adjusted, are shown in parentheses. Significance levels: *** $-1 \%$.

that the reference group for the regressions is the WIN treatment). Additionally, controls for gender, age, round, a subject's risk preferences (the number of risky choices made in the gains domain) and the degree of aversion to losses (the number of risky choices made in the loss domain) are also included. Columns (1) and (2) show the results for contests of size three and six, respectively.

The model in column (1) of Table 2 confirms that for $n=3$, average effort in LOS3 and in W\&L3 contests is significantly higher than in the baseline WIN3 contest. A Wald test also confirms that there is no difference between average effort in LOS3 and W\&L3 $(p=0.40)$. Column (2) shows that, in contests of size six, there is a sizable difference between WIN6 and W\&L6 and between WIN6 and LOS6; hence, the combination of a separate top and bottom prize gives rise to the highest output. Additionally, a Wald test confirms the difference between LOS6 and W\&L6 $(p=0.02)$. The results from columns (1) and (2) thus support what is observed in Figure 3. This leads to our first two results. ${ }^{20}$

Result 1: In contests of size three, there is no difference in average effort between the LOS and WESL treatments, but effort in both of these treatments is higher than in the WIN treatment.

\footnotetext{
${ }^{20} \mathrm{We}$ also explored in more detail the effect of risk preferences. First, we verified randomization across treatments and found no difference in risk preferences by treatment in contests with $n=3$ and $n=6$. In contests of size three, the mean number of risky choices made (out of 10) was 5.2, 4.7, and 5.0 for the WIN, LOS and W\&L contests respectively. In contests of size six, the mean number of risky choices made was $4.7,4.5$ and 4.4 for the WIN, LOS and W\&L contests respectively.
} 

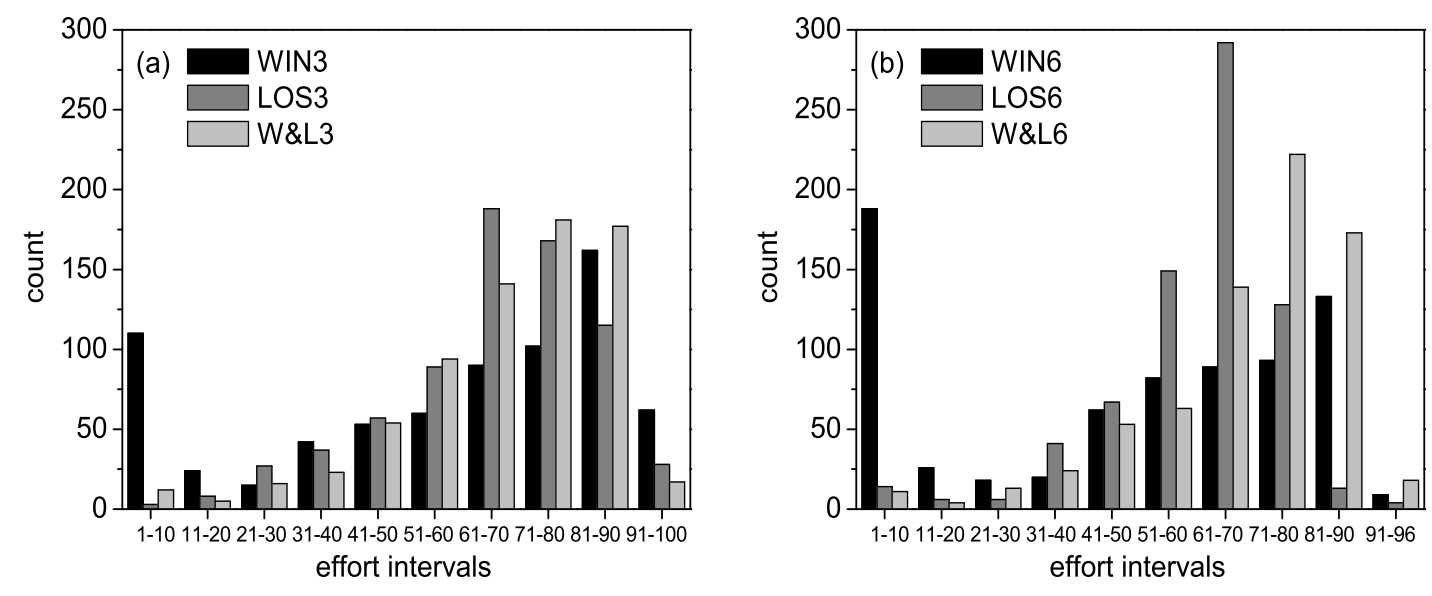

Figure 4: Histograms of effort choices: (a) $n=3$; (b) $n=6$.

Result 2: In contests of size six, average effort is highest in the WEL treatment, lowest in the WIN treatment and intermediate in the LOS treatment.

From the principal's perspective, the preferred mechanism is, of course, the one that generates the highest total effort. The above analysis shows that the mechanism which provides a combination of winner and loser prizes is at least as effective as the other two with respect to total agent effort, and is strictly superior to the other two in contests of size six. Another metric of interest is social efficiency - the total combined net benefits to both the principal and the agents. Since compensation is merely a transfer from the principal to the agents, social efficiency can be calculated at the individual level by taking the difference between effort and the cost of effort, $s_{i}=e_{i}-c g\left(e_{i}\right)$.

Figure 4 presents the histograms of chosen effort for all 20 rounds in contests of size three (panel a) and size six (panel b). Focusing first on panel (b), we see that how the means are arrived at is quite different. In the WIN6 treatment, the distribution of effort appears bimodal. There are many subjects who contribute between 1-10 (the lowest category) and many who contribute 81-90 (the penultimate category). This is in line with the "bifurcation" often observed in experiments on winner contests (see Dechenaux et al. 2012). The variance of effort is quite high, as subjects either compete too much or not enough. In the LOS6 treatment, the opposite is true. There are very few subjects who choose effort at the lower or upper end, with the majority concentrated in the 61-70 range, close to the mean of 60.8. The threat of being last drives up the lower efforts, while the lack of a top prize almost eliminates the higher ones. The W\&L6 mechanism combines both motivations, resulting in a higher overall mean. More specifically, the possibility of being last in the W\&L6 mechanism reduces the incentive to choose a low effort, and at the same time the existence of a top prize gives rise to some higher effort choices. The same 
basic pattern can be observed for contests of size three in panel (a). The distribution of effort in the WIN3 treatment is bimodal, while in the LOS3 and the W\&L3 treatments it appears closer to a normal distribution (if somewhat right-skewed). This is a strong indication that the underlying mechanisms driving effort are the same in contests of size three and of size six.

The differences in distributions of effort lead naturally to differences in social efficiency. Given that we have solved for optimal contracts in the basic model, we can also compute the optimal per capita social efficiency, defined as $\bar{s}=\bar{e}-c g(\bar{e}) \cdot{ }^{21}$ For contests of size three, it is 54.79 and for contests of size six, it is 60.37. The observed average social efficiency in contests of size three is 30.8, 43.3 and 45.2 for the WIN3, LOS3 and W\&L3 treatments, respectively. In contests of size six, average social efficiency is 14.1, 37.4 and 30.7 in the WIN6, LOS6 and W\&L6 treatments respectively. In regressions (not reported here) with individual social efficiency $s_{i}$ as the dependent variable, we find that there is no difference in social efficiency between LOS and W\&L for contests of both sizes $(p=0.63$ for $n=3$ and $p=0.54$ for $n=6$ ). In contests of size three, social efficiency is lower in WIN3 than in the other two mechanisms ( $p<0.01$ for both LOS3 and W\&L3), while in contests of size six there is only a marginal statistical difference between the social efficiency of WIN6 vs. LOS6 $(p=0.08)$ and no differcernce between WIN6 vs. W\&L6 ( $p=0.38)$. In all treatments, average social efficiency is below the optimal level $(p<0.027$ across all six comparisons).

\subsection{Best response}

Given the finding that subjects are not playing the equilibrium strategy, we now explore if subjects are at least best-responding to the off-equilibrium behavior of others. This will relax the assumption that individuals believe all other players are playing the symmetric equilibrium. To do so, we calculate a subject's best response to the effort of others in their group. We then take the absolute difference between what their best response is and what they actually choose. Figure 5 presents the mean of absolute difference between effort and best response by round in each treatment. In this figure, the closer the number is to 0 , the closer the observed effort choices are to a best response.

A couple of things stand out in Figure 5. First, the contests of size three and six look very similar in that the WIN treatment produces efforts furthest from the best response while there doesn't appear to be much difference between the LOS and the W\&L treatments. Interestingly, while there is a slight downward trend in the LOSn and

\footnotetext{
${ }^{21}$ Social efficiency $\bar{s}$ is equal to the agents' equilibrium payoff $\bar{\pi}$ because the firm operates at zero profit.
} 

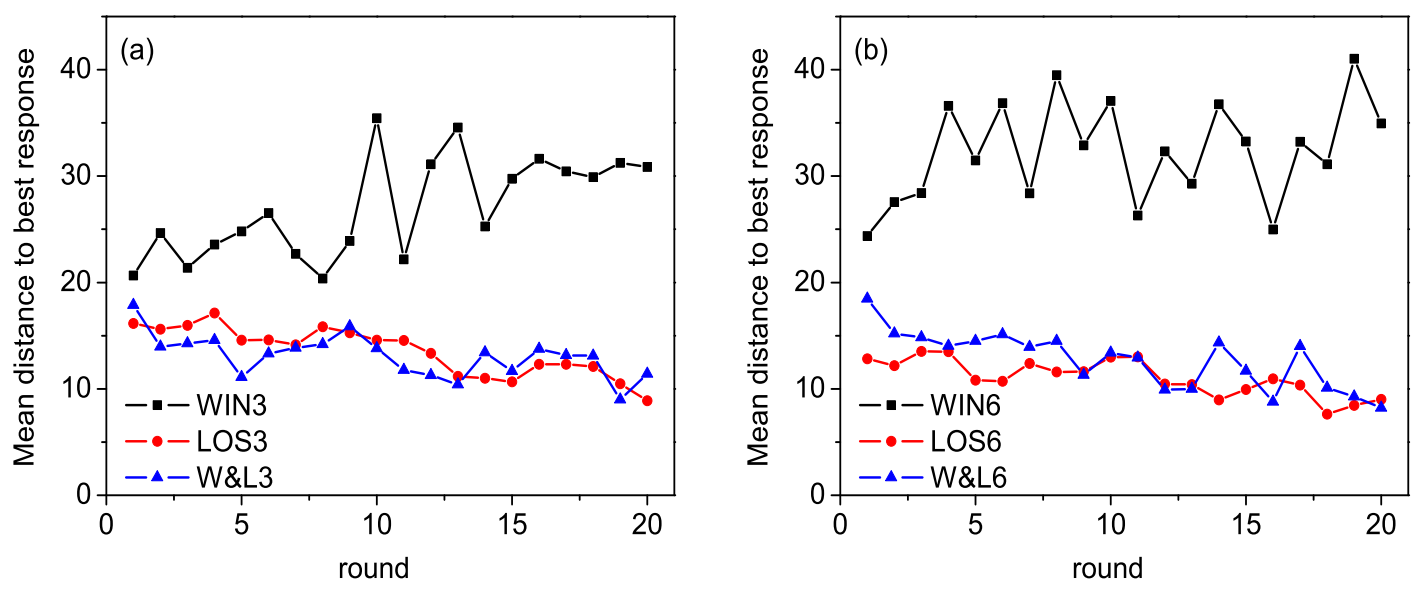

Figure 5: The mean absolute difference between the subject's effort choice and the best response, by treatment and round.

W\&Ln treatments, indicating that subjects become better at best-responding over time, in the WIN $n$ treatments subjects do not seem to be learning to best-respond over time and, if anything, appear to be getting worse.

For more rigorous statistical comparisons, we ran regressions (reported in Table 5 in the Appendix) of the mean absolute distance to best response as the dependent variable. The basic results, shown in columns (1) and (2) of Table 5, confirm what is shown in Figure 5 - subjects are not particularly good at best-responding and they are worse in the WIN than in the LOS or W\&L treatments.

One possible reason the subjects are not doing that well at best-responding - especially in the WIN treatment - is that they are forming incorrect beliefs. Following the final round, we used an incentivized belief elicitation method to gather beliefs about what the subject thought each of their group members chose in the final round. In columns (3) and (4) of Table 5 we present regressions based on the absolute value of the difference between chosen effort and best response to beliefs in the last period. The findings from these regressions are very similar to the results reported in columns (1) and (2). This implies that in the final round, subjects were still not best-responding to their stated (incentivized) beliefs.

\subsection{Analysis of dynamics}

Results 1 and 2 reveal that the mechanisms considered produce differences in effort choices that are not predicted by the basic model and are only partially explained by the QRE framework. The next step is to try and find a suitable explanation which fits our data. Be- 
havior adjustments observed over time in mechanisms such as ours have been traditionally modeled using reinforcement learning and/or directional learning.

The most fundamental property of reinforcement learning is that strategies which have led to bad outcomes are less likely to be used in the future (Roth and Erev 1995). The key feature of the directional learning theory (Selten and Stoecker 1986) is that subjects respond to feedback by updating their actions in the direction of higher expected profits. $^{22}$ If directional learning is applicable in our setting, then we should observe the following patterns: after receiving negative reinforcement (i.e., after being last in the loser tournament or after not winning a winner tournament), a subject should not choose an effort less than or equal to what led to that outcome, implying that a higher effort will be chosen. Likewise, if an agent wins the contest or is not last, this conveys the signal that a lower effort could have potentially led to higher profits; thus, a lower effort will be chosen. A more formal description of the learning model using a combination of reinforcement and directional learning (cf. Grosskopf 2003) is presented in the Appendix. Below we outline the general conjectures of reinforcement and directional learning applied to our setting.

Conjecture 1: Following being last or not being first, subjects will increase their effort. Conjecture 2: Following being first or not being last, subjects will decrease their effort. Conjecture 3: These effects will be lessened over time.

A graphical analysis of Conjectures 1 and 2 is presented in Figure 6. Panel (a) examines behavior before and after being last in treatments LOS $n$ and W\&Ln. Panel (a) shows that, consistent with Conjecture 1, subjects increase their effort after being last. The differences are statistically significant both in the LOS and in the W\&L treatment for both tournament sizes $(p<0.01) .{ }^{23}$

Panel (b) in Figure 6 examines behavior before and after subjects learn that they were not last. We see here that, upon learning that they were not last in the previous round, subjects decrease their effort. Again, this result is statistically significant for all cases, regardless of treatment and tournament size $(p<0.01)$.

In order to check for the robustness of these findings, we present in columns (1) and (2) of Table 3 the results from two regressions, where the dependent variable is the difference in chosen effort between rounds $t$ and $t-1$. The main explanatory variable is

\footnotetext{
${ }^{22}$ Köszegi and Rabin (2006) provide an alternative theory whereby subjects update their reference points. Our paper was not designed to test the various updating mechanisms, and we cannot distinguish between the models (see, e.g., Götte, Hams and Sprenger, 2014, and Andersen, Brandon, Gneezy and List, 2014, for explicit tests of the Köszegi and Rabin model). The simpler learning model we outline appears to be sufficient for explaining our results.

${ }^{23}$ Unless otherwise mentioned, all the $p$-values reported here are a result of a regression where errors are clustered at the subject level.
} 

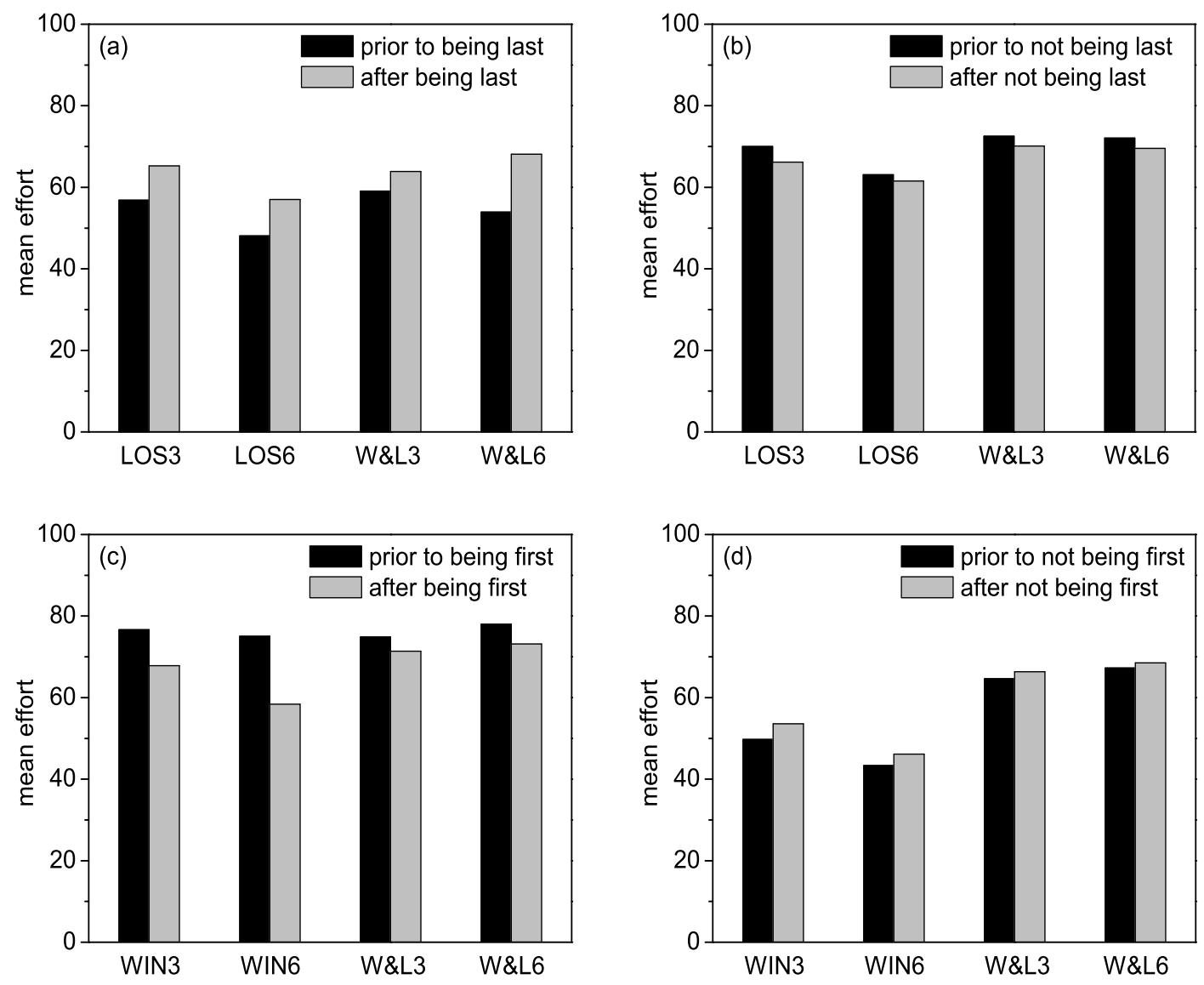

Figure 6: The reaction of subjects in tournaments before and after being reinforced. Panel (a) shows the reaction of subjects before and after being last. Panel (b) shows the reaction of subjects before and after not being last. Panel (c) shows the reaction of subjects before and after winning. Panel (d) shows the reaction of subjects before and after not winning. 


\begin{tabular}{lcccc}
\hline Difference in Effort & $(\mathbf{1})$ & $\mathbf{( 2 )}$ & $\mathbf{( 3 )}$ & $\mathbf{( 4 )}$ \\
& $\mathrm{n}=3$ & $\mathrm{n}=6$ & $\mathrm{n}=3$ & $\mathrm{n}=6$ \\
\hline Constant & -2.23 & -1.58 & $6.42^{*}$ & $7.91^{* * *}$ \\
& $(1.89)$ & $(2.87)$ & $(3.39)$ & $(2.14)$ \\
LagLast & $13.77^{* * *}$ & $11.38^{* * *}$ & & \\
LagFirst & $(2.51)$ & $(2.94)$ & & \\
W\&L & & & $-13.29^{* * *}$ & $-18.53^{* * *}$ \\
& -0.37 & 0.44 & $1.03^{*}$ & $1.3 .33^{* * *}$ \\
Number of Times Last & $-1.00^{* * *}$ & $(0.45)$ & $(0.53)$ & $(0.51)$ \\
& $(0.39)$ & $(0.81)$ & & \\
Number of Times First & & & $1.10^{* * *}$ & $2.27^{* *}$ \\
& & & $(0.36)$ & $(1.06)$ \\
Age & 0.01 & -0.03 & -0.07 & $-0.16^{* * *}$ \\
& $(0.05)$ & $(0.09)$ & $(0.10)$ & $(0.05)$ \\
Risk Aversion & $0.14^{*}$ & -0.16 & 0.14 & 0.01 \\
& $(0.08)$ & $(0.11)$ & $(0.13)$ & $(0.170)$ \\
Loss Aversion & -0.03 & 0.12 & $-0.39^{*}$ & 0.09 \\
& $(0.09)$ & $(0.12)$ & $(0.24)$ & $(0.18)$ \\
Female & -0.50 & 0.01 & -0.17 & $-1.09^{* *}$ \\
& $(0.34)$ & $(0.46)$ & $(0.16)$ & $(0.53)$ \\
Round & 0.020 & $-0.07^{*}$ & $-0.27^{* * *}$ & $-0.16^{* *}$ \\
& $(0.06)$ & $(0.04)$ & $(0.07)$ & $(0.07)$ \\
\hline \# of observations & 1368 & 1368 & 1368 & 1368 \\
\# of clusters & 72 & 72 & 72 & 72 \\
R-squared & 0.07 & 0.11 & 0.03 & 0.04 \\
\hline
\end{tabular}

Table 3: Individual random effects panel regressions on the difference in effort from round $t-1$ to round $t$ where the main explanatory variable is whether the subject was last or first in round $t-1$. Because of this, round 1 is not included in the analysis. Robust standard errors clustered at the individual level are in parentheses. Significance levels: $* * *-1 \%, * *-5 \%, *-10 \%$.

LagLast, which is a dummy variable equal to 1 if the subject was last in round $t-1$. Additionally, there is a variable accounting for the number of times a subject had already been last at the start of a given round, which is meant to capture the decreasing effect of reinforcement over time (see Conjecture 3), as well as a control variable, W\&L, for the type of the contest. Column (1) examines treatments LOS3 and W\&L3 and column (2) examines LOS6 and W\&L6.

In line with Conjecture 1, we see that being last in round $t-1$ causes subjects to increase their chosen effort by a sizable amount, compared to a subject who was not last (see the large and strongly significant coefficient of LagLast in both specifications). In contests of size three, we also observe an inverse relationship between the difference in effort and the number of times a subject was last, as Conjecture 3 predicts. Thus, these results are largely in line with the learning theory.

Turning now to the effect of a single winner prize in treatments WIN $n$ and W\&L $n$, 
panel (c) of Figure 6 shows the response of agents upon winning the contest, and panel (d) shows the response upon not winning the contest. It is evident from panel (c) that, following a win, a subject decreased their effort as predicted by Conjecture 2. The decrease after winning the contest is statistically significant in the WIN as well as in the W\&L contests $(p<0.02)$. Panel $(\mathrm{d})$ of Figure 6 shows that subjects increase their effort upon not winning the contest. This is consistent with Conjecture 1. Again, the difference is highly significant for both tournament mechanisms $(p<0.01)$, although the magnitude is somewhat smaller than what we saw with loser mechanisms.

Columns (3) and (4) in Table 3 report results concerned with how subjects change their behavior in contests involving a single winner prize. The dependent variable is once again the difference in chosen effort from round $t-1$ to round $t$. The main explanatory variable is the dummy LagFirst, which is equal to one if the subject was first in round $t-1$ and zero otherwise. Column (3) examines treatments WIN3 and W\&L3, while column (4) examines treatments WIN6 and W\&L6. Consistent with Conjecture 2 and Figure 6, we document a strong and significant negative impact of winning the contest on effort in the subsequent round. Moreover, this effect is declining with each subsequent reinforcement, as Conjecture 3 suggests.

Result 3: (a) In contests involving single loser prizes, the evolution of play is consistent with basic learning predictions where subjects increase their effort after losing and decrease their effort following not losing.

(b) In contests involving single winner prizes, the evolution of play is consistent with the basic learning predictions where subjects decrease their effort after winning and increase their effort if they do not win.

Taken together, the results so far give us an indication of why winner\&loser contests are generally more effective than the winner-only or loser-only contests. The W\&L mechanism combines the reinforcing features of both contests. These reinforcing features are found to be important regardless of the contest size. To explore this further, we use data from the W\&L contests in order to compare winning and losing, in a setting where both are possible, in terms of the strength of their reinforcing effects. Table 4 presents the results of a regression that includes lags of winning and losing, along with the usual control variables. ${ }^{24}$ The results for contests of size three and six are presented in columns (1) and (2), respectively.

As seen in Table 4, the effect of being last has a larger impact on a subject's subsequent chosen effort, compared to the effect of being first. As a reminder, the variables LagFirst

\footnotetext{
${ }^{24}$ Because we want to isolate the effect of being first or being last, we do not include here the number of times that a subject has won or lost.
} 


\begin{tabular}{lcc}
\hline Difference in Effort & $\mathbf{( 1 )}$ & $\mathbf{( 2 )}$ \\
& $\mathrm{n}=3$ & $\mathrm{n}=6$ \\
\hline Constant & 6.06 & 3.89 \\
& $(4.25)$ & $(3.10)$ \\
LagFirst & $-2.69^{*}$ & -2.61 \\
& $(1.62)$ & $(1.78)$ \\
LagLast & $5.83^{* * *}$ & $16.21^{* * *}$ \\
& $(2.17)$ & $(2.84)$ \\
Age & -0.18 & -0.16 \\
Risk Aversion & $(0.12)$ & $(0.12)$ \\
& 0.12 & $-0.25^{*}$ \\
Loss Aversion & $(0.16)$ & $(0.14)$ \\
Female & -0.10 & 0.23 \\
& $(0.21)$ & $(0.20)$ \\
Round & -1.06 & -0.35 \\
& $(0.67)$ & $(0.58)$ \\
\# of Observations & $-0.13^{*}$ & $-0.09^{*}$ \\
\# of Clusters & $(0.07)$ & $(0.05)$ \\
R-squared & 684 & 684 \\
\hline
\end{tabular}

Table 4: Individual random effects panel regressions on the difference in effort from round $t-1$ to round $t$ in the treatment with both winners and losers where the main explanatory variables are whether the subject won or lost in round $t-1$. Because of this, round one is not included in the analysis. Robust standard errors clustered at the individual level are in parentheses. Significance levels: *** $-1 \%, * *-5 \%, *-10 \%$.

and LagLast are looking at the relative increase or decrease in effort from a subject who was previously first or last. Not only is avoiding being last statistically more significant than trying to be first, but the coefficient on LagLast is more than six times greater in magnitude than the coefficient on LagFirst for contests of size six. ${ }^{25}$ The relatively more effective motivation of avoiding being last indicates why average effort in the LOS treatment is close to that of the W\&L treatments, especially for $n=3$ where negative reinforcement occurs more frequently.

\section{Discussion and conclusion}

In organizations, managers employ incentive schemes which encourage their employees to compete to be best and/or to avoid being the worst of their cohort. The literature up to now has mainly focused on understanding how workers compete for the top prize(s) or behave in tournaments with only two distinct prizes. The goal of this paper is to complement the literature by providing an empirical comparison of how agents compete

\footnotetext{
${ }^{25}$ We also ran these regressions with only LagFirst included, in which case both models give a highly significant effect $(p<0.01)$.
} 
for the top, avoid being last, or both. We do so using a laboratory experiment with three incentive mechanisms: winner tournament, loser tournament, and winner\&loser tournament. We have also varied the size of the tournaments. Although the contracts are calibrated to produce the same efficient employee effort in all treatments, our empirical results have indicated that there are substantial differences in the levels of effort provided in the three mechanisms.

In general, no mechanism extracts higher effort levels from the agents than the one with three distinct prizes, while the commonly studied winner tournament produces the lowest effort. These basic findings are more in line with a QRE model than with the basic equilibrium model, but the comparative statics are not perfectly predicted by QRE. To further explore deviations from those predictions, we examined how far subjects were from best-responding to the behavior of others and found that subjects are furthest from their best response in the winner tournament and, if anything, are getting worse over time. We found no difference in the average distance to best response between the other two mechanisms.

We identify two main drivers of these results. First, we have found that the dynamics of behavior in all mechanisms are consistent with reinforcement and direction learning (Roth and Erev 1995, Selten and Stoecker 1986). Those subjects who had previously been last (or not first) increase their effort in subsequent rounds, while those subjects who were first (or not last) decrease their effort. Second, we have found that competition away from the bottom is more effective than competition for the top at increasing subsequent effort. Taken together these two findings explain why, as the size of the tournament decreases, the outcome in smaller contests which only incorporate a single loser prize will begin to mimic contests which incorporate a winner and a loser prize.

We also find, consistent with the QRE predictions, the highest variance in effort in the winner contests. Because of this high variance, the winner tournament is the least efficient one from an aggregate point of view, while the efficiency achieved in the other two mechanisms is very similar.

Our results show that the static Nash equilibrium and QRE models do not do a great job of predicting our outcomes, although the QRE model does predict many of the observed treatment differences in average effort and effort variance. The dynamics we observed have broader implications to similar environments. More specifically, we find that accounting for initial beliefs and how these beliefs are updated through feedback received does a better job of predicting our results. It can be argued that both the QRE predictions and the equilibrium model are the result of a steady state and that effort in our three treatments would eventually converge to the predicted equilibrium. To that 
end, we do see that in the loser and winner\&loser contests, effort is rising over time and could potentially reach the equilibrium prediction of the Lazear-Rosen model. However, we do not observe the same upward trend in the winner contests. We believe a fruitful direction to extend our study would be to fix initial beliefs and alter the feedback received. With the appropriate control on these two factors, our results imply that the equilibrium predictions may be reached, at least on average.

This paper was designed using a very simple decision environment - a chosen-effort instead of a real-effort task - to give the theory its best chance to succeed. We made this design choice in order to better inform what may need to be changed in the base theory. The simplicity of our design, and the intuitive deviations from theory, also give rise to very practical recommendations. We believe the basic drivers of our results - identified in the dynamics section - to be robust, and additional work can be directed towards understanding how the inclusion of further complications either solidifies or confounds the results. For instance, once real-effort, and the inherent heterogeneity that accompanies it, are tested, the differences between treatments we found may be even stronger given that high-ability subjects will be motivated more by top prizes while lower ability subjects will be motivated more to avoid being last. This is, of course, speculative and we leave it as a future exercise.

Our results inform managers and policy makers on several key issues. Negative and positive incentives are often used to reinforce good or (absence of) bad behavior, and our findings indicate that this goal can be achieved in a tournament setting. In order to elicit the highest amount of effort from their employees, managers should continue to use both mechanisms. Additionally, the reinforcing effect works such that the temporary use of these mechanisms will only lead to the desired outcome in the short term (cf. Conjecture 3). Our results indicate that continuous reinforcement is needed in order to maintain high effort. ${ }^{26}$ Finally, our results can better inform principals who are concerned about the high variance in performance obtained from tournaments. There are several reasons beyond efficiency why a high variance may be troubling to a principal. First, if workers exerting high effort were able to more easily observe the low effort of their co-worker(s), their best response may be to lower their effort in the long term which would result in a drastic decline in a winner tournament. Second, if having predictable quality is desirable, as is the case in many industries, a high variance in effort which results in a high variance in quality (assuming effort and quality are positively related) would be very problematic. In these settings, our results suggest principals should strongly consider using the loser tournament, as this mechanism generates the lowest variance in effort.

\footnotetext{
${ }^{26} \mathrm{~A}$ similar result is found by Mulligan and Schaffer (2011) using simulations.
} 
Lastly, the focus of the prior literature has been on two distinct prizes due to the theoretical finding that two prizes are sufficient for optimality under a variety of assumptions. We find that effort may be different, for quite intuitive reasons, when three distinct prizes are used. Thus, our results suggest that there is promise in mechanisms using more than two distinct prizes.

\section{Acknowledgments}

We would like to thank an Associate Editor, two referees, and seminar participants at the University of Texas Dallas, the University of Innsbruck, the University of Linz and MPI - Munich as well as participants at the 2012 Economic Science Association Meetings in New York and Tucson, the French Experimental Economics Association Meeting in Montpelier and the Southern Economics Association Meeting in New Orleans. Financial support from the Austrian Science Fund (FWF) through project P22772-G11 is gratefully acknowledged.

\section{References}

Akerlof, R., R. Holden. 2012. The nature of tournaments. Economic Theory 51(2): 289 $-313$.

Andersen, S., A. Brandon, U. Gneezy, J. List. 2014 Toward an Understanding of Reference-Dependent Labor Supply: Theory and Evidence from a Field Experiment. No. w20695. National Bureau of Economic Research

Anderson, S., J. Goeree, C. Holt. 1998. A theoretical analysis of altruism and decision error in public goods games. Journal Of Public Economics 70: 297 - 323.

Balafoutas, L., E. G. Dutcher, F. Lindner, D. Ryvkin. 2012. The optimal allocation of prizes in tournaments of heterogeneous agents. University of Innsbruck working paper no. 2012-08

Bell, R., D. McCaffrey. 2002. Bias reduction in standard errors for linear regression with multi-stage samples. Survey Methodology 28(2): 169-182.

Brookins, P., D. Ryvkin. 2014. An experimental study of bidding in contests of incomplete information. Experimental Economics 17(2): 245 - 261. 
Bull, C., A. Schotter, K. Weigelt. 1987. Tournaments and piece rates: An experimental study. Journal of Political Economy 95(1): 1-33.

Camerer, C., D. Lovallo. 1999. Overconfidence and excess entry: An experimental approach. American Economic Review 89(1): 306-318.

Carpenter, J., P. H. Matthews, J. Schirm. 2010. Tournaments and office politics: Evidence from a real effort experiment. American Economic Review 100(1): 1-18.

Casas-Arce, P., F. A. Martinez-Jerez. 2009. Relative performance compensation, contests, and dynamic incentives. Management Science 55(8): 1306-1320.

Cason, T. N., W. A. Masters, R. M. Sheremeta. 2010. Entry into winner-take-all and proportional-prize contests: An experimental study. Journal of Public Economics 94(9-10): 604-611.

Chowdhury, S., R. Sheremeta, T. Turocy. 2012.Overdissipation and convergence in rentseeking experiments: Cost structure and prize allocation rules. SSRN working paper

Dechenaux, E., D. Kovenock, R. Sheremeta. 2012. A Survey of experimental research on contests, All-Pay Auctions and Tournaments. SSRN working paper

Dickinson, D. 2001. The carrot vs. the stick in work team motivation. Experimental Economics 4 (1): 107-124.

Eriksson, T., S. Teyssier, M. C. Villeval. 2009. Self-selection and the efficiency of tournaments. Economic Inquiry 47(3): 530-548.

Falk, A., E. Fehr, D. Huffman. 2008. The power and limits of tournament incentives. Discussion Paper University of Zurich.

Fischbacher, U. 2007. z-Tree: Zurich toolbox for readymade economic experiments. Experimental Economics 10(2): 171-178.

Gächter, S., E. Johnson, A. Herrmann. 2010. Individual-level loss aversion in riskless and risky choices. University of Nottingham Centre for Decision Research and Experimental Economics Discussion Paper, No. 2010-20.

Götte, L., A. Harms, and C. Sprenger. 2014. Randomizing Endowments: An Experimental Study of Rational Expectations and Reference-Dependent Preferences. IZA Discussion Paper No. 8639 
Gneezy, U., M. Niederle, A. Rustichini. 2003. Performance in competitive environments: Gender differences. Quarterly Journal of Economics 118(3): 1049-1074.

Goeree, J., C. Holt, T. Palfrey. 2002. Quantal response equilibrium and overbidding in private-value auctions. Journal of Economic Theory 104: 247-272.

Gradstein, M., K. Konrad. 1999. Orchestrating rent-seeking contests. Economic Journal 109: $536-545$.

Greiner, B. 2004. An online recruitment system for economic experiments. In: Forschung und wissenschaftliches Rechnen, ed. Kremer and Macho, 79-93. Göttingen: GWD

Grosskopf, B. 2003. Reinforcement and directional learning in the ultimatum game with responder competition. Experimental Economics 6(2): 141-158.

Gürtler, O., M. 2011. Kräkel. Dismissal tournaments. University of Cologne working paper

Harbring, C., B. Irlenbusch. 2003. An experimental study on tournament design. Labour Economics 10(4): 443-464.

Harbring, C., B. Irlenbusch. 2008. How many winners are good to have? On tournaments with sabotage. Journal of Economic Behavior and Organization 65(3): 682-702

Harbring, C., B. Irlenbusch. 2012. Sabotage in tournaments: Evidence from a laboratory experiment. Management Science. 57(4): 611-627

Höchtl, W., R. Kerschbamer, R. Stracke, U. Sunde. 2014. Incentives vs. selection in promotion tournaments: Can a designer kill two birds with one stone? Managerial and Decison Economics DOI: 10.1002/mde.2666

Holt, C. A., S. K. Laury. 2002. Risk aversion and incentive effects. American Economic Review 92(5): 1644-1655.

Konrad, K. A. 2009. Strategy and dynamics in contests, Oxford University Press.

Köszegi, B., M. Rabin. 2006. A model of reference-dependent preferences. The Quarterly Journal of Economics 121(4): 1133-1165.

Kräkel, M. 2000. Relative deprivation in rank-order tournaments. Labour Economics $7(4): 385-407$.

Lazear, E. P. 1995. Personnel economics. Cambridge, MA: MIT Press. 
Lazear, E. P., S. Rosen. 1981. Rank-order tournaments as optimum labor contracts. Journal of Political Economy 89(5): 841-864.

Lim, W., A. Matros, T. Turocy. 2012. Bounded rationality and group size in Tullock contests: experimental evidence. Working paper. Available at http://ihome.ust.hk/ wooyoung/index.ht 20120615.pdf

List, J.A., van Soest, D., Stoop, J., \& Zhou. H. 2010. On the role of group size in tournaments: Theory and evidence from lab and field experiments. Working paper, University of Chicago, Chicago.

Masclet, D., C. Noussair, S. Tucker, M. C. Villeval. 2003. Monetary and non-monetary punishment in the voluntary contributions mechanism. American Economic Review 93(1): 366-380.

McLaughlin, K. J. 1988. Aspects of tournament models: A survey. Research in Labor Economics 9: 225-256.

McKelvey, R., T. Palfrey. 1995. Quantal response equilibrium for normal form games. Games and Economic Behavior 10: 6-38.

Mirrlees J. 1975. The Theory of moral hazard and unobservable behavior. Mimeo, Nuffield College.

Moldovanu, B., A. Sela, X. Shi. 2012. Carrots and sticks: prizes and punishments in contests. Economic Inquiry, 50(2): 453-462

Mulligan, J., R. B. Schaefer. 2011. A new hope for rank and yank. Journal of Leadership and Organizational Studies 18(3): 385-396.

Nalebuff, B. J., J. E. Stiglitz. 1983. Prizes and incentives: Towards a general theory of compensation and competition. Bell Journal of Economics 14(1): 21-43.

Noussair, C., S. Tucker. 2005. Combining monetary and social sanctions to promote cooperation. Economic Inquiry 43(3): 649-660.

O'Flaherty, B., A. Siow. 1995. Up-or-out rules in the market for lawyers. Journal of Labor Economics 13: 709-735.

Orrison, A., A. Schotter, K. Weigelt. 2004. Multiperson tournaments: An experimental examination. Management Science 50(2): 268-279. 
Rosen, S. 1986. Prizes and incentives in elimination tournaments. American Economic Review 76(4): 701-715.

Roth, A., I. Erev. 1995. Learning in extensive-form games: Experimental data and simple dynamic models in the intermediate term. Games and Economic Behavior 8(1): $164-212$.

Ryvkin, D., A. Ortmann. 2008. The predictive power of three prominent tournament formats. Management Science 54(3): 492-504.

Schotter, A., K. Weigelt. 1992. Asymmetric tournaments, equal opportunity laws, and affirmative action: Some experimental results. Quarterly Journal of Economics 107(2): 511-539.

Selten, R. and Stoecker, R. 1986. End behaviour in sequences of finite prisoner's dilemma supergames: A learning theory approach. Journal of Economic Behavior and Organization $7(1)$ : 47-70.

Sheremeta, R. 2011. Contest design: an experimental investigation. Economic Inquiry 49: 573-590.

Sheremeta, R. 2010. Experimental comparison of multi-stage and one-stage contests. Games and Economic Behavior 68(2): 731-747.

Sunde, U. 2009. Heterogeneity and performance in tournaments: a test for incentive effects using professional tennis data. Applied Economics 41(25): 3199-3208.

Sutter, M., S. Haigner, M. Kocher. 2010. Choosing the stick or the carrot? Endogenous institutional choice in social dilemma situations. Review of Economic Studies 77(4): $1540-1566$.

\section{$9 \quad$ Appendix}

\subsection{Analysis of best response}

In the regression analysis in Table 5, the dependent variable is the absolute value of the difference between a subject's choice and their best response. The independent variables are the same as those used in Table 2 except we add an interaction of treatment with 


\begin{tabular}{lcccc}
\hline Effort & $\mathbf{( 1 )}$ & $\mathbf{( 2 )}$ & $\mathbf{( 3 )}$ & $\mathbf{( 4 )}$ \\
& $\mathrm{n}=3$ & $\mathrm{n}=6$ & $\mathrm{n}=3$ & $\mathrm{n}=6$ \\
\hline Constant & $22.09^{* *}$ & 15.58 & 27.52 & $48.22^{* * *}$ \\
LOS & $(5.44)$ & $(14.16)$ & $(37.57)$ & $(11.28)$ \\
W\&L & $-4.48^{*}$ & $-15.44^{* * *}$ & $-24.55^{* * *}$ & $-26.69^{* * *}$ \\
& $(2.54)$ & $(2.44)$ & $(2.48)$ & $(2.84)$ \\
Age & $-5.96^{* * *}$ & $-12.63^{* * *}$ & $-21.65^{* * *}$ & $-25.79^{* * *}$ \\
& $(2.18)$ & $(2.72)$ & $(3.68)$ & $(1.93)$ \\
Risk Aversion & -0.02 & 0.40 & 0.28 & -0.14 \\
& $(0.29)$ & $(0.51)$ & $(1.06)$ & $(0.30)$ \\
Loss Aversion & -0.42 & -0.13 & -0.79 & -1.81 \\
& $(0.61)$ & $(0.34)$ & $(1.19)$ & $(1.11)$ \\
Female & -0.17 & -0.03 & 0.76 & -1.71 \\
& $(0.87)$ & $(0.36)$ & $(1.92)$ & $(1.68)$ \\
Round & 1.41 & 3.89 & -0.09 & 2.27 \\
& $(1.60)$ & $(2.39)$ & $(5.10)$ & $(1.68)$ \\
Round*LOS & $0.55^{* *}$ & $0.24^{* * *}$ & & \\
Round*W\&L & $(0.25)$ & $(0.01)$ & & \\
& $-0.89^{* * *}$ & $-0.47^{* * *}$ & & \\
\hline \# of observations & $(0.27)$ & $(0.04)$ & & \\
\# of clusters & $-0.74^{* * *}$ & $-0.60^{* * *}$ & & \\
\hline
\end{tabular}

Table 5: OLS regression results. Standard errors, clustered by session and BRL adjusted, are in parentheses. In columns (1) and (2), the dependent variable is the absolute difference between effort and best response. In columns (3) and (4), the dependent variable is the absolute difference between effort and best response to beliefs in the last period. Significance levels: $* * *-1 \%, * *-5 \%, *-10 \%$. 
round to account for the diverging time trends. Columns (1) and (2) report the basic results for contests of size three and six respectively.

Looking first at the results for contests of size three, we see that subjects in LOS and W\&L are better at best responding than subjects in the WIN treatment. We also see from the positive sign on the coefficient for round that in the WIN treatment, they are getting worse at best responding over time. Wald tests confirm that in the LOS and W\&L treatments, subjects are actually improving over time $(p<0.01$ for both). Turning to the results for contests of size six, we also see that subjects are better at best responding in the LOS and W\&L than in the WIN treatment. The same dynamics seen in contests of size three are also apparent in contests of size six. Over time, subjects do appear to be getting better at best responding in the LOS and the W\&L treatment $(p<0.01$ and $p=0.05$ respectively).

\subsection{Learning dynamics}

In this section, we describe the reinforcement and directional learning mechanisms more formally. Suppose that in round $t$ subject $i$ has some propensity $q_{j}^{(i)}(t)$ to choose effort $j$ which results in payoff $\pi_{j}^{(i) a}(t) .{ }^{27}$ The subject chooses effort $j$ if they believe that the expected payoff from doing so, $\pi_{j}^{(i) e}(t)$, is greater than the payoff from choosing any other effort, i.e., $\pi_{j}^{(i) e}(t)>\pi_{-j}^{(i) e}(t)$. With the expected payoff in round $t$ as a reference point, the outcome, $\pi_{j}^{(i) a}(t)$, will be viewed as positive (negative) reinforcement if $\pi_{j}^{(i) a}(t)>\pi_{j}^{(i) e}(t)$ $\left(\pi_{j}^{(i) a}(t)>\pi_{j}^{(i) e}(t)\right)$. We assume that, having observed the outcome of round $t$, subjects update their propensities so that $q_{j}^{(i)}(t+1)=q_{j}^{(i)}(t)+\pi_{j}^{(i) a}(t)-\pi_{j}^{(i) e}(t)$ and $q_{-j}^{(i)}(t+1)=$ $q_{-j}^{(i)}(t)$. The probability, $p_{j}^{(i)}(t)$, of subject $i$ choosing effort $j$ in round $t$ is given by

$$
p_{j}^{(i)}(t)=\frac{q_{j}^{(i)}(t)}{\sum_{h=1}^{J} q_{h}^{(i)}(t)}
$$

Here, $J$ is the highest possible effort.

There are two main implications to this simple model. The first is that strategies which lead to payoffs which are lower than expected will have a lower probability of being played in the future. The second implication can be seen by noticing that because probabilities $p_{j}^{(i)}(t)$ are concave in propensities, reinforcement has a diminishing effect over time.

The above model does a nice job of explaining the dynamics that could lead to the

\footnotetext{
${ }^{27}$ We will assume the initial propensities $q_{j}^{i}(1)$ are fixed and will not explore what may cause subjects to develop initial propensities.
} 
behavior we observe in the loser treatments when a subject is ranked last. It dictates that a subject will update their probabilities based solely on the wrong expectations of payoff from choosing effort $j$, i.e., the information they receive informs them that a higher effort could have potentially led to a higher payoff. More specifically, we can think that subjects are updating expectations such that $\pi_{j}^{(i) e}(t+1)=\pi_{j}^{(i) a}(t)$. What is missing from this analysis is the behavior when a subject realizes they are not last (or are first). Figure 3 hints that the reaction in the two scenarios is not symmetric since average effort is not declining over time in all of the treatments. If the round-to-round updating in the two scenarios were symmetric, a downward time trend in effort would be observed since there are more people who are not last (n-1) than who are last (1). The direction of updating, however, is different in this scenario. If a subject realizes they are not last, this does not mean they had wrong expectations about the payoff they would receive from choosing effort $j$; it means they had the wrong expectations about the payoffs from the other strategies, i.e., the outcome informs them that a lower effort could have potentially led to a higher payoff. More formally, we can say that a subject's expected payoff from choosing any effort is a function of their beliefs about the payoffs they can receive from any other

effort $j$. For example, $\pi_{j^{\prime}}^{(i) e}(t)=\alpha_{j j^{\prime}}(t) \pi_{j}^{(i) e}(t)$ where $\alpha_{j j^{\prime}}$ is a parameter accounting for the distance between $j$ and another effort $j^{\prime}$. As $j^{\prime}$ gets closer to $j, \alpha_{j j^{\prime}}$ approaches 1 from above or below. Notice that if a player thinks that choosing effort $j$ is optimal, then $\alpha_{j j^{\prime}}<1 .^{28}$ In each round then, a subject updates their expected payoff from choosing any effort and they update how this payoff relates to similarly chosen efforts.

The implication of a structure where there exists a correlation in profits as defined is obvious and results in the asymmetries observed. This can be explained by noticing that by choosing a higher effort in round $t$ after losing in round $t-1$ results in a higher cost, but these costs are offset by the much larger gain attainable if the subject is not last. This is in contrast to a subject who finds they are not last. The gain from choosing a lower effort is small since it is only a cost savings, but the potential loss if the subject is last is quite large. Or, put more simply, the potential payoff gain in round $t$ from large deviations from the effort chosen in round $t-1$ is much greater if the subject was last in round $t-1$ than if they were not last.

\subsection{Experimental instructions}

\section{Instructions for WIN6:}

Welcome to an experiment on decision making. We thank you for your participation!

\footnotetext{
${ }^{28}$ This is similar in spirit to the "experimentation" parameter in the Roth-Erev Model.
} 
The experiment will be conducted on the computer. All decisions and answers will remain confidential and anonymous. Please do not talk to each other during the experiment. If you have any questions, please raise your hand and we will come by and answer it.

During the experiment, you and the other participants will be asked to make a series of decisions. Your payment will be determined by your decisions as well as the decisions of the other participants according to the following rules.

During the experiment you will be earning tokens. At the end of the experiment, tokens will converted to Euros at a rate of 2000 tokens $=1$ Euro. Today's experiment consists of several parts. The instructions for the first part are given below.

\section{Rounds and Groups:}

The first part consists of 20 rounds. The computer will choose 4 rounds at random for which to pay you. You will not be told which rounds will be paid until the conclusion of all parts of the experiment.

At the beginning of each round you will be randomly matched in a Group with 5 other participants. This means that in each round the groups are re-matched, so that they will not be the same (unless by chance). You will never be told the identity of those in your Group and they will never be told your identity.

\section{Tasks:}

Your task in today's experiment is to choose a number between 1 and 96. You will enter your chosen number in the blank box on your computer screen labeled "Number Chosen" and then hit "Continue." The sheet labeled "Decision Costs" shows you the cost in tokens associated with each number. Notice that higher the number chosen, the higher the associated cost. Each member in your Group has the same cost sheet as you. In each round, all Group members choose his/her numbers simultaneously. You will not know the number chosen by any of your Group members when you make your choice and likewise, they will not know the number you chose when they make their choice.

After all group members have made their choice, the computer will draw a random number between -44 and 44, independently for each member of your group. All numbers in this range are equally likely and each number drawn does not affect the number drawn for someone else in your Group. This number will be added (or subtracted) from your chosen number to make your total number.

\section{Payoffs:}

The computer will compare your total number with the total number of those in your Group. The person with the highest total number will receive 14,667 tokens while 
the remaining 5 members of the group will receive 5867 tokens. The cost of each chosen number will be subtracted from this amount to give you the total payment for each round should that round be chosen for payment.

At the end of each round you will be shown the random number chosen for you, your resulting total number, and whether your total number is higher than anyone's in your Group.

\section{Example:}

Let's go through an example. Suppose you chose the number 50 and the other members of your group chose 32, 65, 80, 46 and 18. Also suppose that the random number drawn for you was 26 and the random number drawn for the other members of your Group were -12, 41, -32, 13 and 7 respectively. This would mean your total number is $50+26=76$. The total numbers of the other group members would be $20,106,48,59$ and 25. In this example, you have the second highest number and thus would receive 5867 $342=5534$ tokens if this round were randomly chosen for payment. Notice that the 633 tokens corresponds to the cost associated with a chosen number of 50 .

If on the other hand, you had chosen 85 and all other chosen numbers and random draws remained the same, you would have a total number of $85+26=111$. This would mean you would have the highest total number and would receive $14667-4247=10420$ tokens if this round were randomly chosen for payment.

As a final point, once you have made your decisions or are finished viewing the results please hit the continue button. No one can move to the next round until everyone in the experiment has clicked on this button so make sure to pay attention to the screen to keep the experiment moving along.

Are there any questions? 


\section{Decision costs}

\begin{tabular}{|c|c|c|c|c|c|c|c|}
\hline $\begin{array}{l}\text { Chosen } \\
\text { Number }\end{array}$ & $\begin{array}{l}\text { Token } \\
\text { Cost }\end{array}$ & $\begin{array}{l}\text { Chosen } \\
\text { Number }\end{array}$ & $\begin{array}{l}\text { Token } \\
\text { Cost }\end{array}$ & $\begin{array}{l}\text { Chosen } \\
\text { Number }\end{array}$ & $\begin{array}{l}\text { Token } \\
\text { Cost }\end{array}$ & $\begin{array}{l}\text { Chosen } \\
\text { Number }\end{array}$ & $\begin{array}{l}\text { Token } \\
\text { Cost }\end{array}$ \\
\hline 1 & 3 & 29 & 120 & 57 & 488 & 85 & 4247 \\
\hline 2 & 5 & 30 & 127 & 58 & 515 & 86 & 4909 \\
\hline 3 & 8 & 31 & 134 & 59 & 543 & 87 & 5752 \\
\hline 4 & 11 & 32 & 141 & 60 & 573 & 88 & 6851 \\
\hline 5 & 14 & 33 & 148 & 61 & 606 & 89 & 8328 \\
\hline 6 & 17 & 34 & 156 & 62 & 641 & 90 & 10395 \\
\hline 7 & 20 & 35 & 164 & 63 & 678 & 91 & 13434 \\
\hline 8 & 23 & 36 & 173 & 64 & 719 & 92 & 18223 \\
\hline 9 & 27 & 37 & 181 & 65 & 763 & 93 & 26561 \\
\hline 10 & 30 & 38 & 191 & 66 & 810 & 94 & 43539 \\
\hline 11 & 33 & 39 & 200 & 67 & 862 & 95 & 89639 \\
\hline 12 & 37 & 40 & 210 & 68 & 918 & 96 & 353185 \\
\hline 13 & 41 & 41 & 221 & 69 & 980 & & \\
\hline 14 & 45 & 42 & 232 & 70 & 1048 & & \\
\hline 15 & 49 & 43 & 243 & 71 & 1122 & & \\
\hline 16 & 53 & 44 & 255 & 72 & 1205 & & \\
\hline 17 & 57 & 45 & 268 & 73 & 1296 & & \\
\hline 18 & 61 & 46 & 281 & 74 & 1398 & & \\
\hline 19 & 66 & 47 & 295 & 75 & 1512 & & \\
\hline 20 & 70 & 48 & 310 & 76 & 1641 & & \\
\hline 21 & 75 & 49 & 326 & 77 & 1786 & & \\
\hline 22 & 80 & 50 & 342 & 78 & 1952 & & \\
\hline 23 & 85 & 51 & 360 & 79 & 2142 & & \\
\hline 24 & 91 & 52 & 378 & 80 & 2362 & & \\
\hline 25 & 96 & 53 & 397 & 81 & 2619 & & \\
\hline 26 & 102 & 54 & 418 & 82 & 2921 & & \\
\hline 27 & 108 & 55 & 440 & 83 & 3281 & & \\
\hline 28 & 114 & 56 & 463 & 84 & 3715 & & \\
\hline
\end{tabular}

